\title{
Age-Associated Endothelial Dysfunction in Rat Mesenteric Arteries: Roles of Calcium-Activated $\mathrm{K}^{+}$Channels $\left(\mathrm{K}_{\mathrm{ca}}\right)$
}

\author{
E. ZHOU ${ }^{1}$, D. QING ${ }^{2}$, J. LI ${ }^{2}$
}

${ }^{1}$ Department of Surgery, Second Xiangya Hospital of Central South University, Changsha, Hunan, P.R. China, ${ }^{2}$ Department of Medicine, Second Xiangya Hospital of Central South University, Changsha, Hunan, P.R. China

Received February 9, 2009

Accepted November 25, 2009

On-line April 20, 2010

\section{Summary}

Age-associated changes in large blood vessels were characterized by increased arterial wall thickness, luminal dilation and impaired endothelial function. But little is known about the effect of age on structural and functional changes in small resistance arteries. The mechanisms underlying age-associated endothelial dysfunction in rat mesenteric resistance arteries were investigated in the present study. Small rat mesenteric arteries were excised and cannulated, and vascular endothelial functions were tested by acetylcholine (ACh). Our experiments showed (1) endotheliumdependent vasorelaxation induced by $\mathrm{ACh}$ was reduced in aged mesenteric arteries; (2) blockade of $\mathrm{K}_{\mathrm{ca}}$ channels markedly reduced the vasodilation in young and adult rats, the resultant reduction in aged rats was much smaller compared with young and adult rats; (3) inhibition of endothelial nitric oxide synthase (NOS) resulted in a significant reduction of vasodilation in young and adult, but there was a smaller reduction in aged rats. The results suggest that (1) endothelial function was impaired in mesenteric arteries of aged rats; (2) both $\mathrm{K}_{\mathrm{ca}}$ channels and nitric oxide (NO) contribute together to the ACh-induced vasorelaxation in small mesenteric arteries, and (3) both the impairment of $\mathrm{K}_{\mathrm{ca}}$ channel function and decreased NO account for the age-related endothelial dysfunction.

\section{Key words}

Aging - Endothelial dysfunction - Potassium channels • Mesenteric artery • Acetylcholine

\section{Corresponding author}

E. Zhou, Department of Surgery, Second Xiangya Hospital of Central South University, Changsha, Hunan 410011, P.R. China. Fax: +86-731-5361500. E-mail: enxiangzhou@gmail.com or

D. Qing, Department of Medicine, Second Xiangya Hospital of Central South University, Changsha, Hunan 410011, P.R. China. Fax: +86-731-5361500. E-mail: duxinqing@gmail.com

\section{Introduction}

The process of aging is associated with marked changes in the vascular system that can lead to the development of cardiovascular diseases. It is known that increasing age induces structural and functional alterations in large conduit arteries (Santhanam et al. 2008) and small resistance arteries as well (Laurant et al. 2004, Briones et al. 2007). With age, the central aorta dilates (Lakatta 1993) and the arterial wall thickness of large arteries increases (Nagai et al. 1998). In small resistance arteries, age-related enlargement of vascular lumen and increased thickness of vascular wall have been reported recently (Briones et al. 2007, Laurant et al. 2004). Because age-associated cardiovascular disease is the leading cause of morbidity and mortality in industrialized and some developing countries, the mechanisms that initiate and propagate changes in the aging vasculature are currently in the focus of increasing investigation.

One of the major vascular functional changes with normal aging is the age-related endothelial dysfunction. Endothelial cells control the tone of the underlying vascular smooth muscle by releasing several constricting factors such as endothelin and prostaglandin $\mathrm{H}_{2}$, and endothelium-derived relaxing factors, including nitric 
oxide (NO), reactive oxygen species (ROS), potassium ions $\left(\mathrm{K}^{+}\right)$, and metabolites of arachidonic acid. Age-related endothelial dysfunction may be due to an alteration of the balance between endothelium-derived relaxing and constricting factors (Matz et al. 2000). The reduced endothelium-dependent vasorelaxation with age has been characterized by reduced agonist-mediated vasodilation (Minamino and Komuro 2008), declined flow-induced vasodilation (Csiszar et al. 2002, Muller-Delp et al. 2002), and by decreased sensitivity of arteriolar endothelium to fluid shear stress (Sun et al. 2002). To date most studies have focused on the effects of aging on endotheliumdependent NO-mediated vasodilation. Endotheliumdependent vasorelaxation in aorta and large proximal arteries is dependent almost entirely on NO, and is very sensitive to increased endogenous superoxide $\left(\mathrm{O}_{2}{ }^{-}\right)$ (Davidge et al. 1998, Knock et al. 2006). Moreover, in small resistance arteries, the effect of age on endotheliumdependent vasorelaxation has not been extensively studied (Matz et al. 2000). In distal resistance arteries, including those of mesenteric, pulmonary and cerebral circulation, however, endothelium-derived hyperpolarization factors (EDHF) participates significantly in agonist-induced vasorela-xation as the vessel diameter decreases (Sobey 2001). Hyperpolarization through potassium channel opening is a fundamental mechanism for vasorelaxation of small vessels. Calcium-activated $\mathrm{K}^{+}$channels $\left(\mathrm{K}_{\text {ca }}\right)$ are key effectors in the control of endothelium-dependent EDHFevoked vasorelaxation (Hilgers and Webb 2007). There are three types of $\mathrm{K}_{\mathrm{ca}}$ channels in vascular cells, including large-conductance $\mathrm{K}_{\mathrm{ca}}\left(\mathrm{BK}_{\mathrm{ca}}\right)$ channels in vascular smooth muscle cells; intermediate $\left(\mathrm{IK}_{\mathrm{ca}}\right)$ and small-conductance $\mathrm{K}_{\mathrm{ca}}\left(\mathrm{SK}_{\mathrm{ca}}\right)$ channels in endothelial cells. Activation of $\mathrm{K}_{\mathrm{ca}}$ channels on vascular cells contributes to agonist inducedvasorelaxation in rat (Dimitropoulou et al. 2007) and rabbit mesenteric arteries (Khan et al. 1993, Zhang et al. 2007). The endothelial cell $\mathrm{IK}_{\mathrm{ca}}$ and $\mathrm{SK}_{\mathrm{ca}}$ channels are especially important for EDHF-mediated relaxation and hyperpolarization in resistance arteries (Dora et al. 2008). Impaired $\mathrm{K}^{+}$channel function or reduced hyperpolarization in vascular cells has been detected in various diseased conditions such as hypertension (Hilgers and Webb 2007), diabetes (Fukao et al. 1997) and ischemia/reperfusion (Ko et al. 2008, Sobey 2001). But the role of $\mathrm{K}_{\mathrm{ca}}$ channels during aging is still unclear. Given that small resistance arteries contribute to the regulation of blood pressure and local blood flow, EDHF and $\mathrm{K}_{\mathrm{ca}}$ channels are implicated in control of blood pressure and regional blood flow in mammalian tissues in vivo, and may be altered under pathophysiological conditions such as hypertension and diabetes as well as advancing aging. Changes in molecular composition and function of $\mathrm{K}_{\mathrm{ca}}$ channels in resistance arteries may therefore be a fundamental event contributing to the progression of arterial dysfunction during age. However, EDHF and $\mathrm{K}_{\mathrm{ca}}$ channel functional changes in healthy aging are not completely understood and require further studies. In the present study, we investigated the roles of $\mathrm{K}_{\mathrm{ca}}$ channels underlying the age-related vascular functional changes, and provided evidences for impaired potassium channel function as well as reduced release of NO in the acetylcholine (ACh)-induced vasodilation in small mesenteric arteries of aged rats.

\section{Materials and Methods}

\section{Vessel preparation}

Male Sprague-Dawley rats aged 3-6 months (young), 10-12 months (adult), and more than 24 months (aged) were used in the present study. The animals were fed standard rat chow and had free access to tap water, and maintained in the Institute of Experimental Animals following the procedures approved by the China Central South University Advisory Committee for Animal Resources. Rats were anesthetized with pentobarbital sodium $(50 \mathrm{mg} / \mathrm{kg}$ intraperitoneally). The mesenteric vascular bed was excised and placed on a cooling plate containing cold $\left(0-4 \quad{ }^{\circ} \mathrm{C}\right) \quad 3$-( $\mathrm{N}$-morpholino) propanesulfonic acid (MOPS) buffered physiological saline solution (see below) containing $1 \%$ bovine serum albumin. The second to fourth branches of the arteries (200-300 $\mu \mathrm{m}$ in diameter) were cut, cleaned of adherent connective tissue, transferred to an organ bath $(2.5 \mathrm{ml}$ volume) mounted on the stage of an inverted video microscope (Zeiss 100TV). Arterial segments were cannulated at both ends onto glass micropipettes and secured, and the lumen of the vessel was filled with MOPS-buffered solution containing $1 \%$ albumin. The transmural pressure was set at $80 \mathrm{~mm} \mathrm{Hg}$ and continuously monitored. Neither transluminal flow nor oxygenation was applied to the cannulated vessels. The internal diameter of the vessels was recorded by a computerized diameter tracking system (Diamtrak, Montech Pty Ltd., Australia).

\section{Experimental procedures}

After cannulation, the mesenteric arteries were superfused continuously with a MOPS-buffered physiological saline solution $\left(37.5^{\circ} \mathrm{C}, \mathrm{PH} 7.3\right)$ of the 
following composition (in mmol/l): $144 \mathrm{NaCl}, 3 \mathrm{KCl}$, $2.5 \mathrm{CaCl}_{2}, 1.4 \mathrm{MgSO}_{4}, 2.0$ pyruvate, 5.0 glucose, 0.02 ethylenediaminetetraacetic acid (EDTA), and 2.0 3-(N-morpholino) propanesulfonic acid (MOPS), 1.21 $\mathrm{NaH}_{2} \mathrm{PO}_{4}$. The extraluminal solution was warmed from room temperature to $37.5{ }^{\circ} \mathrm{C}$. After 30 -min equilibration, the vessels were exposed to $10 \mu \mathrm{mol} / 1$ phenylephrine (PE), which produced a near maximum contraction response in vessels from all age groups. After the contraction reached a steady state, increasing dose of acetylcholine (ACh) were applied to incubation bath to elicit vasorelaxation. The vessel internal diameter was recorded once the vessel reached a steady state.

For vasorelaxation mechanism study, the following inhibiting experiments were conducted: $10 \mu \mathrm{mol} / 1 \mathrm{~N}^{\omega}$-monomethyl-L-arginine (L-NMMA; a NO synthase inhibitor); $1 \mu \mathrm{mol} / 1$ charybdotoxin $\left(\mathrm{BK}_{\mathrm{ca}}\right.$ and $\mathrm{IK}_{\mathrm{ca}}$ channel inhibitor); $1 \mu \mathrm{mol} / 1$ apamin $\left(\mathrm{SK}_{\mathrm{ca}}\right.$ inhibitor). ACh-induced vessel diameter changes were recorded before and after 30-min incubation with these inhibitors. All chemicals were obtained from Sigma, St. Louis.

\section{Data collection and statistical analysis}

All data are presented as mean \pm S.E.M. Six to ten vessels from at least 6 rats were used in each group. The vessel diameter changes were presented as percentages $(\%)$ of dilation of the preconstricted vessels, calculated as follows: $\%$ of vasodilation $=\left[\left(\mathrm{D}_{\text {agonist }}{ }^{-}\right.\right.$ $\left.\left.D_{\text {base }}\right) /\left(D_{\max }-D_{\text {base }}\right)\right] \times 100$, where $D_{\max }$ is the maximum diameter of the vessel at $80 \mathrm{~mm} \mathrm{Hg}$ at room temperature before equilibration, $D_{\text {base }}$ is the vessel diameter at steady contraction state induced by $\mathrm{PE}$ before the $\mathrm{ACh}$ stimulation, and $\mathrm{D}_{\text {agonist }}$ is the diameter of the vessel after ACh stimulation. With this method, the maximum dilation is represented as $100 \%$, and baseline diameter is $0 \%$. Comparisons were made with the use of paired Student's $t$ test or ANOVA with a post-hoc Bonferroni test, as appropriate. The acceptable level of significant was defined as $P<0.05$.

\section{Results}

Increased body weight in aged rats was observed. Body weight was greater $(\mathrm{P}<0.01)$ in aged $(586.4 \pm 11.2 \mathrm{~g}, \mathrm{n}=8)$ than in adult $(412.3 \pm 8.6 \mathrm{~g}, \mathrm{n}=8)$ and in young (313.6 $\pm 4.8 \mathrm{~g}, \mathrm{n}=8)$ rats. The passive maximum internal diameters at $80 \mathrm{~mm} \mathrm{Hg}$ of intravascular pressure were $245.67 \pm 8.36 \mu \mathrm{m}, 259.50 \pm 8.49 \mu \mathrm{m}$ and $266.33 \pm$ $9.40 \mu \mathrm{m}$ in young, adult and aged rats respectively. No significant increase was observed in small mesenteric artery internal diameters $(\mathrm{P}>0.05, \mathrm{n}=10$ for all three groups) in our preparation.

Phenylephrine (PE) contracted the cannulated mesenteric resistance arteries in a concentrationdependent manner (data not shown). The contraction induced by $10 \mu \mathrm{mol} / \mathrm{l} \mathrm{PE}$ was slightly increased in old rats. PE caused vessel contraction of $48.01 \pm 2.89 \%$ $(127.83 \pm 5.49 \mu \mathrm{m})$ in young, $50.65 \pm 1.23 \%(128.20 \pm$ $5.81 \mu \mathrm{m})$ in adult, and $54.96 \pm 3.70 \%(172.17 \pm 6.20 \mu \mathrm{m})$ in aged rats.

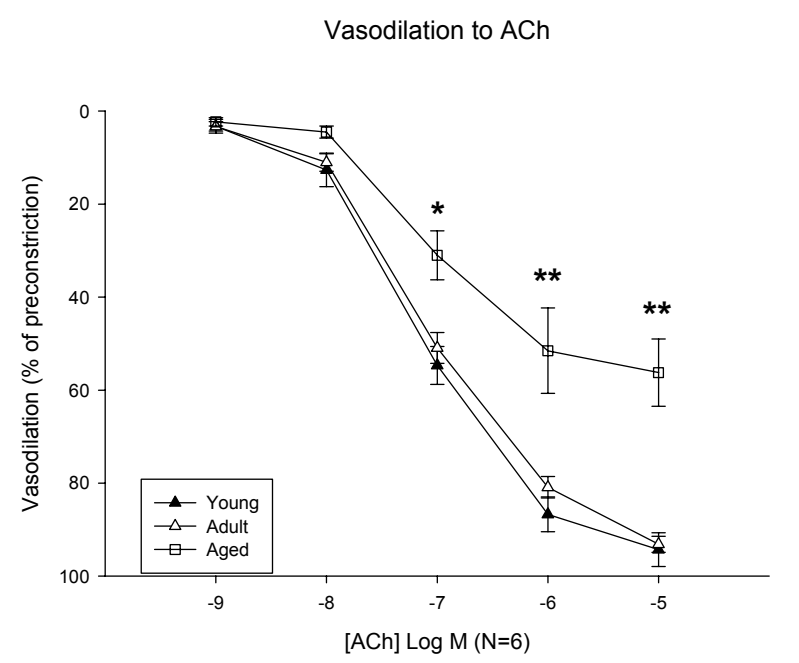

Fig. 1. Concentration-response curves to ACh in PEpreconstricted small mesenteric arteries. ACh induced vasodilation of mesenteric arteries in a dose-dependent manner in young, adult and aged rats, but vasodilation was significantly declined in vessels from aged rats at the concentration $100 \mathrm{nmol} / \mathrm{l}, 1 \mu \mathrm{ml} / \mathrm{l}$ and $10 \mu \mathrm{mol} / \mathrm{l}$. ** $\mathrm{P}<0.001$, * $\mathrm{P}<0.05$.

ACh-induced vasorelaxation in young, adult and aged rats are shown in Figure 1. Vascular relaxation responses to $\mathrm{ACh}$ were abolished by removal of endothelium (data not shown) in young rats, which supports that ACh-induced vasorelaxation in rat mesenteric arteries is endothelium-dependent. In young and adult groups, ACh induced similar vasorelaxation of rat mesenteric artery in a dose-dependent manner. There was no difference of ACh-induced dilation between young and adult groups. 1 and $10 \mu \mathrm{mol} / 1 \mathrm{ACh}$ evoked a vasodilation of $86.72 \pm 1.54 \quad \% \quad(229.83 \pm 7.49 \mu \mathrm{m})$, $94.31 \pm 3.47 \% \quad(238.83 \pm 7.76 \mu \mathrm{m}) \quad$ in young, and $80.89 \pm 0.94 \%(234.43 \pm 7.99 \mu \mathrm{m}), 93.16 \pm 1.71 \%(250.50 \pm$ $8.24 \mu \mathrm{m})$ in adult rats. However, the relaxation induced by $\mathrm{ACh}$ in the aged rats was significantly decreased at all ACh concentration except concentration of 1 and 10 nmol/1 (Fig. 1, P<0.001). 1 and $10 \mu \mathrm{mol} / 1 \mathrm{ACh}$ induced a 

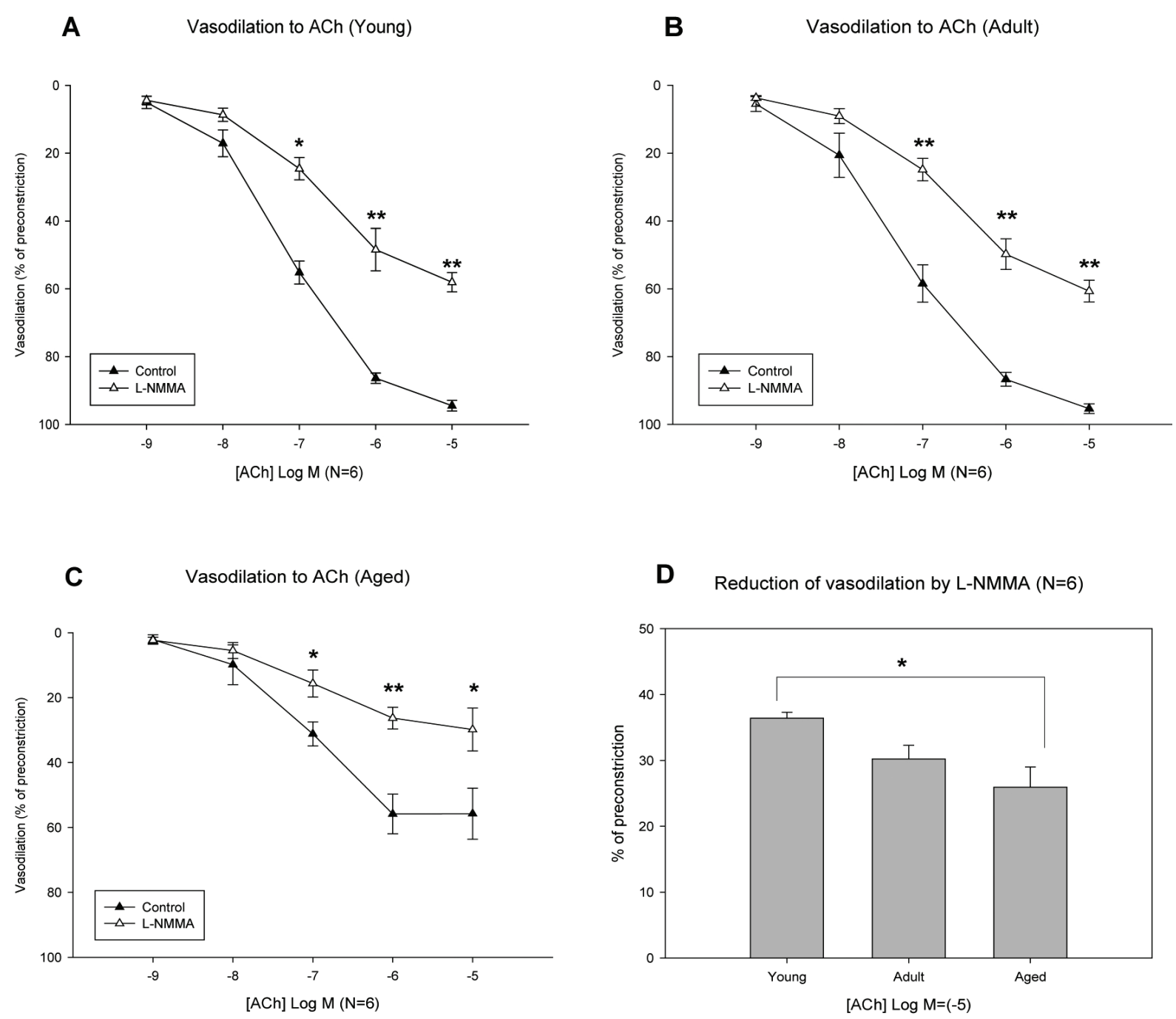

Fig. 2. Concentration-response curves to $A C h$ before/after incubation with $10 \mu \mathrm{mol} / \mathrm{l} L-N M M A$ in PE-preconstricted small mesenteric arteries. L-NMMA incubation resulted in a significant reduction in vasodilation to ACh in young (A), adult (B) and aged rats (C) as well. But the reduction was declined in aged rats compared with young rats $(D)$. $* * P<0.001, * P<0.05$.

dilation of $51.55 \pm 3.75 \% \quad(222.83 \pm 10.31 \mu \mathrm{m})$ and $56.25 \pm 2.96 \%(225.00 \pm 9.20 \mu \mathrm{m})$. In young and adult rats, $10 \mu \mathrm{mol} / \mathrm{l}$ ACh evoked almost fully dilation of mesenteric arteries. But in aged rat, $1 \mu \mathrm{mol} / 1 \mathrm{ACh}$ induced the maximum vasodilation (less than $60 \%$ ) (Figs 1 and 2C), $10 \mu \mathrm{mol} / \mathrm{l}$ (Fig. 1) and even $100 \mu \mathrm{mol} / \mathrm{l}$ (data not shown) could not caused more vasorelaxation.

Nitric oxide is a well-known vasodilator in many vessel beds. PE-induced contractile responses were potentiated in all groups by L-NMMA (a specific NOS inhibitor). The contraction was $67.77 \pm 2.96 \%$ in young, $67.91 \pm 2.32 \%$ in adult, and $68.01 \pm 2.02 \%$ in aged rats after L-NMMA treatment. In young and adult rats, L-NMMA significantly reduced the vasorelaxation evoked by ACh (Figs 2A and 2B). After 30-min incubation of vessels with $10 \mu \mathrm{mol} / 1 \mathrm{~L}-\mathrm{NMMA}$, ACh- evoked dilation was reduced from $86.37 \pm 3.54 \%$ $(234.83 \pm 4.87 \mu \mathrm{m}), 94.46 \pm 1.57 \%(245.67 \pm 5.73 \mu \mathrm{m})$ to $48.45 \pm 2.56 \%(164.17 \pm 6.90 \mu \mathrm{m})$ and $58.07 \pm 1.16 \%$ $(181.00 \pm 4.37 \mu \mathrm{m})$ at $1 \mu \mathrm{mol} / 1$ and $10 \mu \mathrm{mol} / \mathrm{l}$, respectively. In adult rats, L-NMMA incubation evoked a similar inhibition (from $86.70 \pm 2.03 \%$ and $95.36 \pm 1.42 \%$ to $52.60 \pm 2.18 \%$ and $65.14 \pm 2.25 \%$ ). In aged rats, L-NMMA also markedly inhibited the vasorelaxation induced by ACh (Fig. 2C). The vasodilation was reduced from $55.83 \pm 2.50 \%(222.50 \pm 6.34 \mu \mathrm{m})$ and $55.76 \pm 3.22 \%$ $(222.00 \pm 7.02 \mu \mathrm{m})$ to $26.31 \pm 1.37 \%(186.83 \pm 5.19 \mu \mathrm{m})$ and $29.83 \pm 2.70 \% \quad(190.84 \pm 6.35 \mu \mathrm{m})$ at $\mathrm{ACh}$ concentration of $1 \mu \mathrm{mol} / 1$ and $10 \mu \mathrm{mol} / 1$. Nevertheless, the reduction of vasodilation caused by incubation of L-NMMA was declined in aged rats (Fig. 2D) compared with young rats. 
A Vasodilation to ACh (Young)

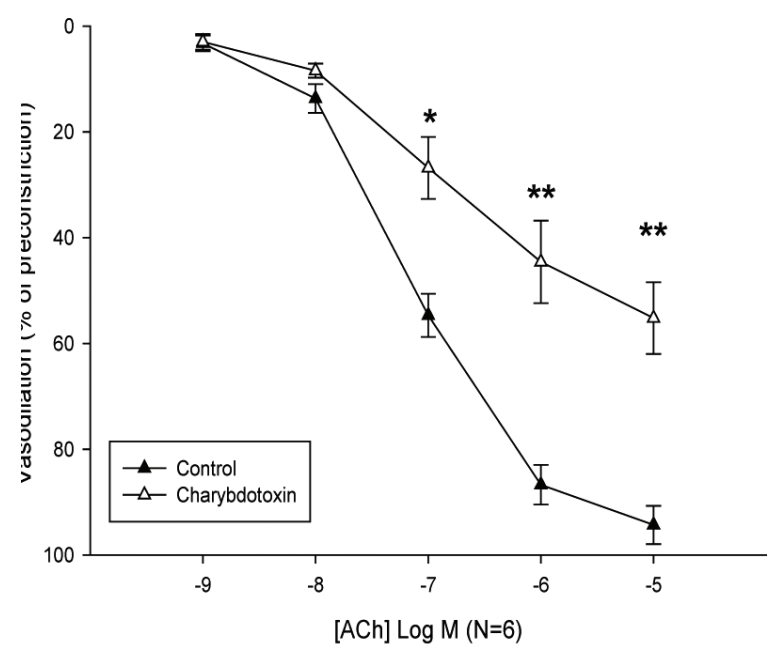

C Vasodilation to ACh (Aged)

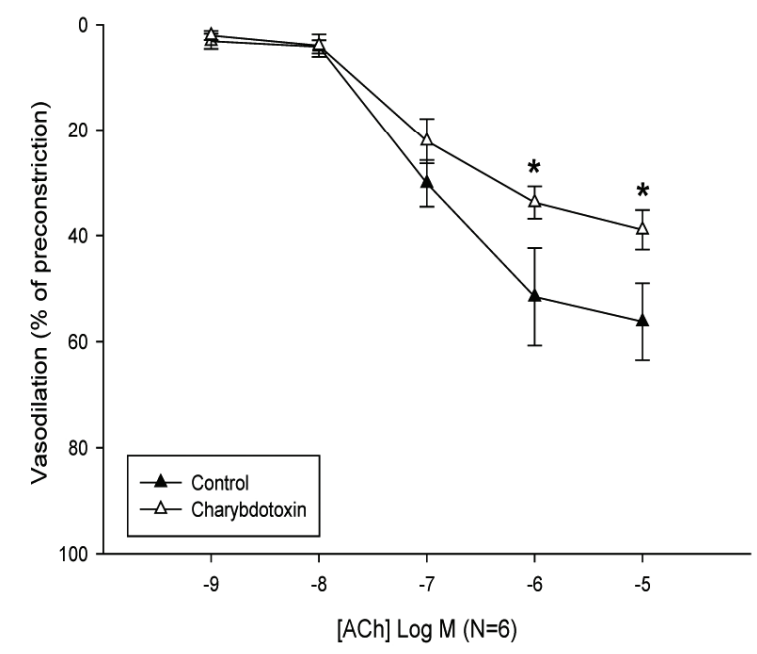

B Vasodilation to ACh (Adult)

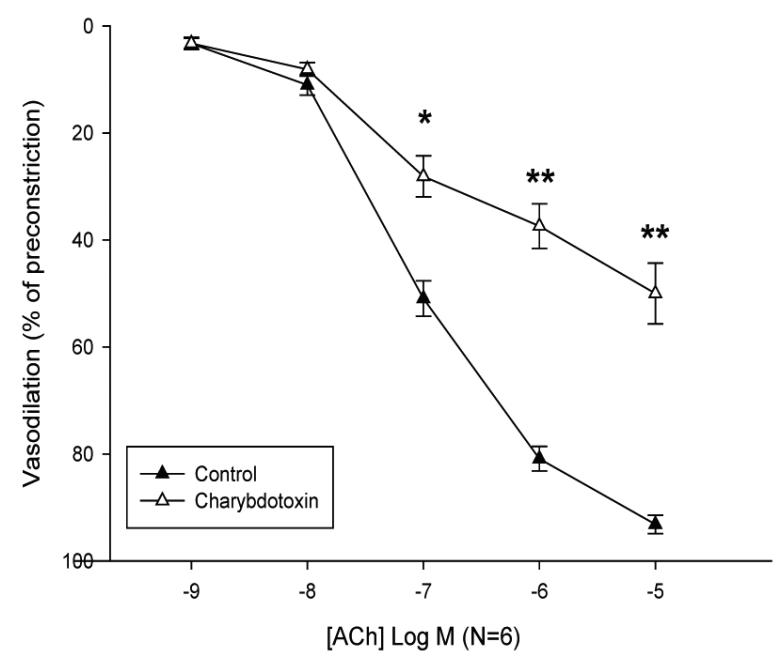

D Reduction of vasodilation by charybdotoxin $(\mathrm{N}=6)$

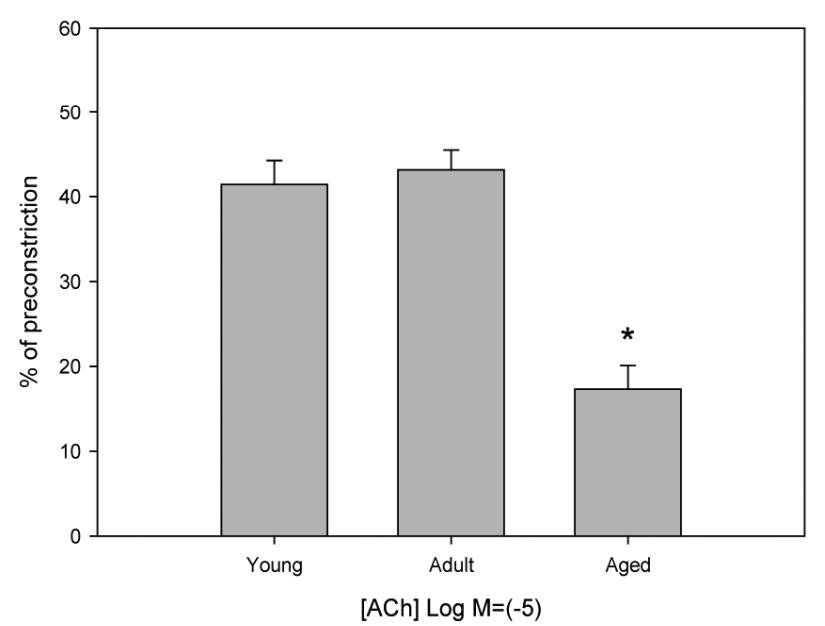

Fig. 3. Concentration-response curves to ACh before/after incubation with $1 \mu \mathrm{mol} / \mathrm{l}$ charybdotoxin in PE-preconstricted small mesenteric arteries. Incubation with charybdotoxin reduced the vasodilation to ACh in young (A), adult (B) and aged rats (C), but charybdotoxin resulted in a significantly lower reduction in aged rats compared with young and adult rats $(D)$. ${ }^{* *} P<0.001, * P<0.05$.

Calcium-activated potassium channels $\left(\mathrm{K}_{\mathrm{ca}}\right)$ play a central role in EDHF-mediated vasorelaxation in small mesenteric arteries (Hilgers and Webb 2007, Dora et al. 2008). In the present study, we used charybdotoxin to block $\mathrm{IK}_{\mathrm{ca}}$ and $\mathrm{BK}_{\mathrm{ca}}$ channels, apamin to block $\mathrm{SK}_{\mathrm{ca}}$ channels. Incubation of vessels of young rats with charybdotoxin, ACh-induced vasorelaxation was reduced from $86.72 \pm 3.76 \%(230.83 \pm 7.49 \mu \mathrm{m}), 94.31 \pm 3.61 \%$ $(238.84 \pm 7.76 \mu \mathrm{m})$ to $44.59 \pm 7.80 \%(180.50 \pm 5.57 \mu \mathrm{m})$ and $55.21 \pm 6.77 \%(192.83 \pm 4.55 \mu \mathrm{m})$ at 1 and $10 \mu \mathrm{mol} / 1$ Ach, respectively (Fig. 3A, $\mathrm{P}<0.001$ ). The reduced vasodilation was similar in adult rats (Fig. 3B). In aged rats, charybdotoxin also inhibited the ACh-induced vasodilation (Fig. 3C). The vasodilation was reduced from $51.55 \pm 3.75 \%(220.86 \pm 10.31 \mu \mathrm{m}), 56.25 \pm 3.91 \%$ $(225.00 \pm 9.20 \mu \mathrm{m})$ to $33.78 \pm 3.05 \%(190.17 \pm 8.83 \mu \mathrm{m})$ and $38.93 \pm 1.52 \quad \% \quad(196.16 \pm 8.17 \mu \mathrm{m}) \quad$ at $\quad \mathrm{ACh}$ concentration of 1 and $10 \mu \mathrm{mol} / \mathrm{l}$. But the reduction was much less than that in young and adult rats (Fig. 3D). Incubation with apamin partially inhibited the AChinduced vasorelaxation in young and adult rats (Figs 4A and 4B). Vasodilation in young rats was reduced from $86.72 \pm 3.76 \%, \quad 94.31 \pm 3.61 \% \quad$ to $60.56 \pm 3.87 \%$ $(199.33 \pm 6.55 \mu \mathrm{m})$ and $74.45 \pm 6.54 \%(216.00 \pm 7.78 \mu \mathrm{m})$ at ACh concentration of $1 \mu \mathrm{mol} / 1$ and $10 \mu \mathrm{mol} / 1$, respectively (Fig. $4 \mathrm{~A}, \mathrm{P}<0.01$ ). In aged rats, incubation of 
A Vasodilation to ACh (Young)

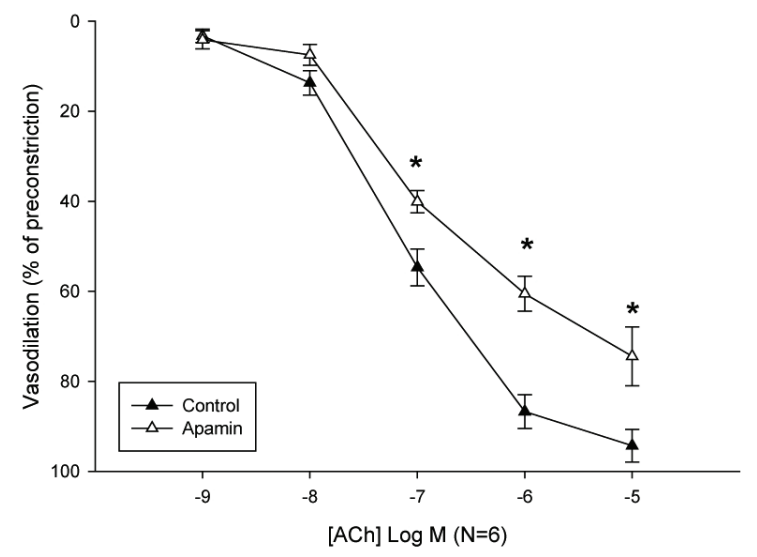

C

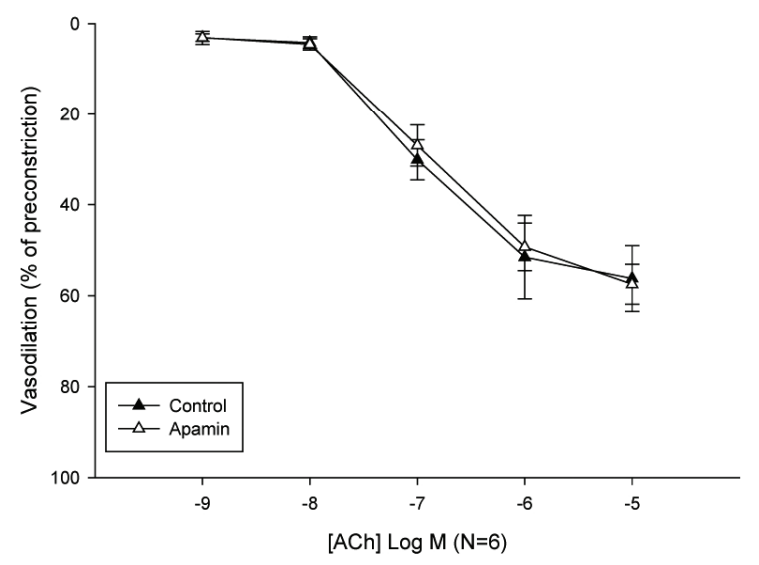

B Vasodilation to ACh (Adult)

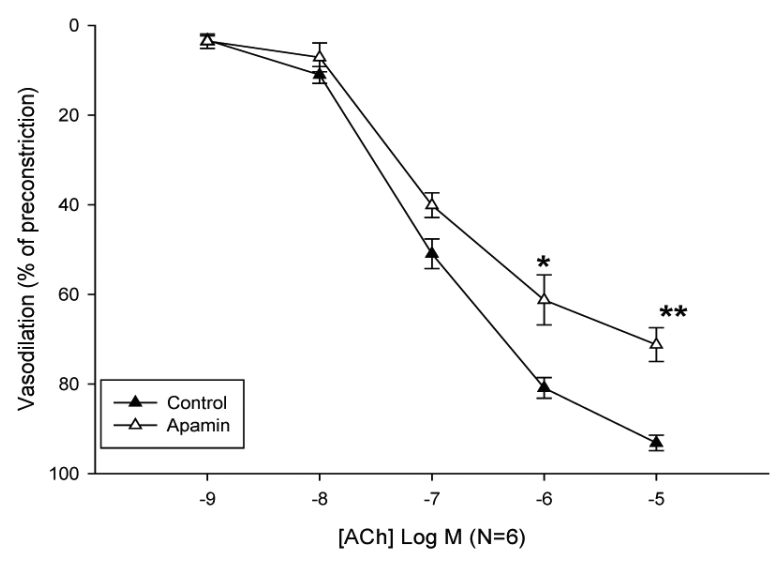

D Reduction of vasodilation by apamin ( $\mathrm{N}=6)$

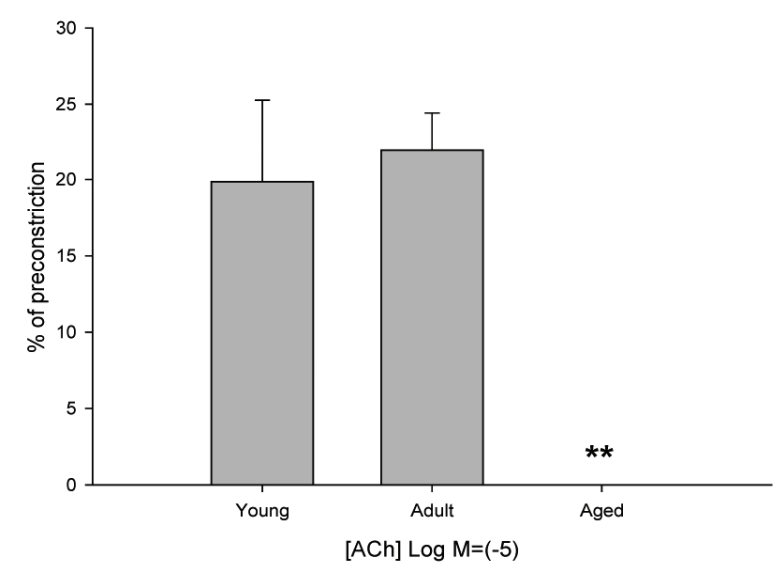

Fig. 4. Concentration-response curves to $A C h$ before/after incubation with $1 \mu \mathrm{mol} / \mathrm{l}$ apamin in PE-preconstricted small mesenteric arteries. Apamin resulted in a significant reduction in vasodilation to ACh in young (A) and adult rats (B). Incubation of apamin did not have any effect on the ACh-induced vasodilation in aged rats (C). Comparison of the reduction of vasodilation by apamin was shown in Fig. 4D. $* * \mathrm{P}<0.001, * \mathrm{P}<0.05$.

vessels with apamin did not have significant effect on the dilation (Fig. 4C). Ach-evoked vasodilation was $49.30 \pm 5.21 \%(208.50 \pm 10.46 \mu \mathrm{m})$ and $57.50 \pm 4.41 \%$ $(218.00 \pm 9.31 \mu \mathrm{m})$ after apamin treatment compared to $51.55 \pm 3.75 \%$ and $56.25 \pm 2.96 \%$ at 1 and $10 \mu \mathrm{mol} / 1$ concentration. Figure 4D shows the reduction evoked by apamin at ACh concentration of $1 \mu \mathrm{mol} / \mathrm{l}$. Apamininduced reduction was declined with advancing age.

To further analyze the interactions of NO and $\mathrm{K}_{\mathrm{ca}}$ channels in aged rats, we tested the small mesenteric arteries with combined incubation of apamin, charybdotoxin and L-NMMA. Combined use of apamin, charybdotoxin and L-NMMA almost abolished the AChinduced vasorelaxation in young rats (Fig. 5A). The dilation was only $13.92 \pm 3.06 \%$ at $1 \mu \mathrm{mol} / 1 \mathrm{ACh}$ and $17.84 \pm 3.50 \%$ at $10 \mu \mathrm{mol} / 1$. Similar results were obtained from adult rats (Fig. 5B). In aged rats, vasodilation after combined application of apamin, charybdotoxin and L-NMMA was $10.83 \pm 2.74 \%$ at $1 \mu \mathrm{mol} / 1$ and $14.35 \pm 1.59 \%$ at $10 \mu \mathrm{mol} / 1$ (Fig. 5C). Vasodilation after combined incubation of apamin, charybdotoxin and L-NMMA in aged rat was similar to that in young and adult rats (Fig. 5D, $\mathrm{P}>0.05$ ).

\section{Discussion}

In this study, we provided evidence for agerelated impairment of endothelial function in rat small 
A

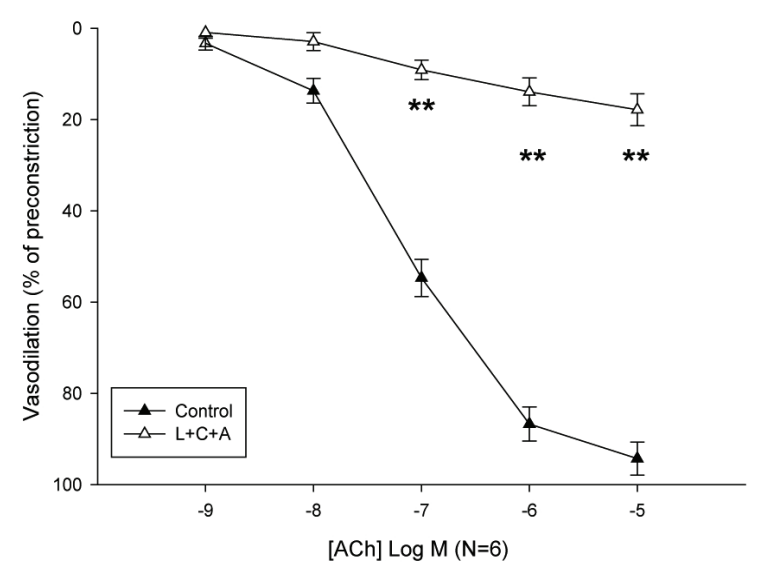

C

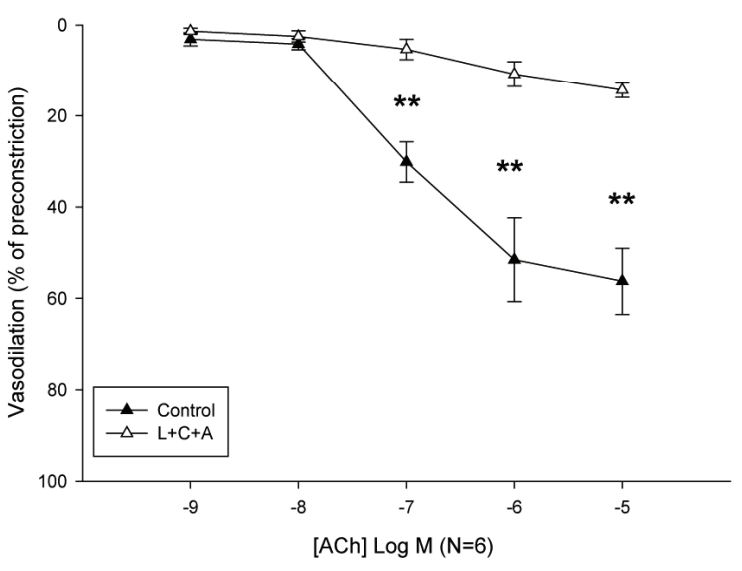

B

Vasodilation to ACh ( Adult)

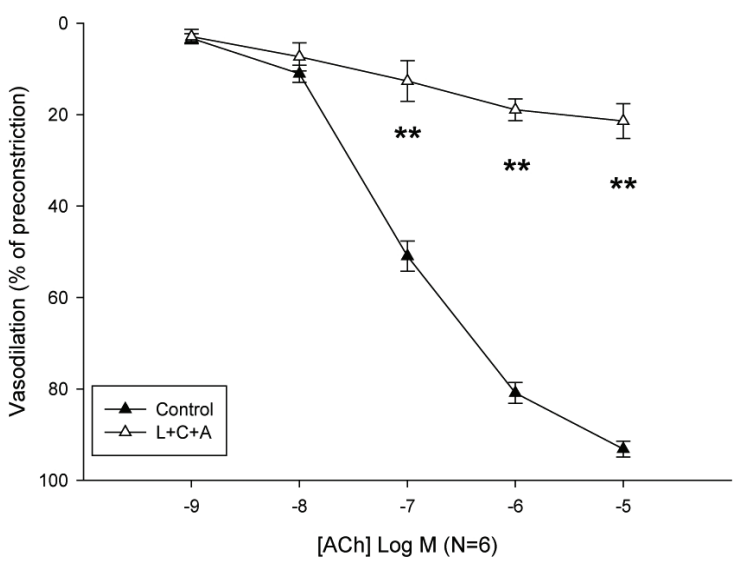

D Vasodilation to ACh after incubation of L-NMMA, charybdotoxin and apamin

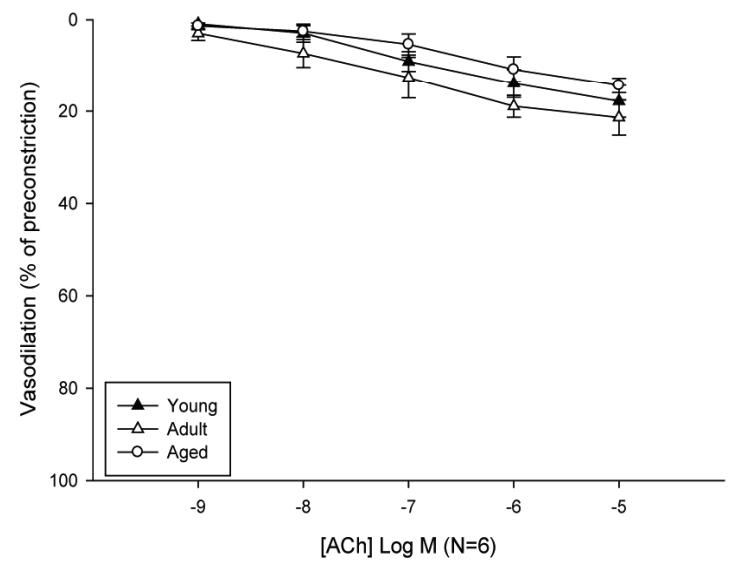

Fig. 5. Concentration-response curves to ACh before/after a combined incubation with $10 \mu \mathrm{mol} / \mathrm{I} \mathrm{L}-\mathrm{NMMA}, 1 \mu \mathrm{mol} / \mathrm{l}$ charybdotoxin and $1 \mu \mathrm{mol} / \mathrm{l}$ apamin $(\mathrm{L}+\mathrm{C}+\mathrm{A})$ in PE-preconstricted small mesenteric arteries. The combined incubation almost abolished vasodilation induced by $\mathrm{ACh}$ in young $(\mathrm{A})$, adult $(\mathrm{B})$ and in aged rats $(\mathrm{C})$. ACh-induced vasodilation was similar after combined incubation in three rat groups (D). ** $\mathrm{P}<0.001$.

mesenteric arteries. The major findings were (1) $\mathrm{K}_{\mathrm{ca}}$ channels and NO contribute to the dilation induced by $\mathrm{ACh}$ in rat small mesenteric arteries; (2) endotheliumdependent vasorelaxation was impaired in aged rats; (3) functionally defective $\mathrm{K}_{\mathrm{ca}}$ channels and reduced production of $\mathrm{NO}$ contribute to the age-associated impairment of endothelial function.

Vascular aging has been relatively well characterized in aorta and large proximal arteries. Ageassociated changes in blood vessels include increased arterial wall thickness, luminal dilatation and impaired endothelial function (Minamino and Komuro 2008). However, little is known about the effects of age on small resistance arteries. In the present study, we showed that the endothelium-dependent vasorelaxation to $\mathrm{ACh}$ in the small resistance mesenteric arteries declined with age. ACh-induced vasodilation was abolished by removal of endothelium, supporting the fact that ACh-induced vasorelaxation in rat mesenteric arteries is endotheliumdependent. In vessels from aged rats, ACh-induced vasorelaxation was markedly impaired compared to that in vessels from young and adult rats, indicating an ageassociated impairment of endothelial function in small mesenteric arteries. In the present study, animal body weight increased with age, but we did not see an agerelated increase in vascular internal diameter. In our 
preparation, we chose vessels at almost the same size to fit our cannulation system, which may explain that there is no increase in vessel internal diameter.

Mechanisms accounting for the age-related endothelial dysfunction include an increase in oxidative stress, reduced endothelial NO synthase (eNOS) activity and NO production (Taddei et al. 2001, Sun et al. 2004, Minamino and Komuro 2008). The mechanism of increase in oxidative stress comprises increased production of reactive oxygen species (ROS), decreased NO bioavailability, and subsequent formation of peroxynitrite $\left(\mathrm{ONOO}^{-}\right)$, which is well documented in aorta and large proximal arteries (Santhanam et al. 2008). In old rat aorta, endothelial NO synthase (eNOS) expression was increased, but NO production and downstream signaling (cGMP) was decreased (Cernadas et al. 1998). However, the mechanisms accounting for vasculature aging in distal resistance arteries may be different. Both the activity of eNOS and the release of NO have been suggested to be reduced in aged small resistance arteries (Amrani et al. 1996). eNOS mRNA and eNOS protein expression were reduced in the aging coronary (Csiszar et al. 2002) and skeletal muscle vasculatures (Woodman et al. 2002). In mesenteric arteries from aged rats, although eNOS protein expression was not different from that of young rats, shear stress-induced synthesis of NO was reduced (Sun et al. 2004). In our cannulated mesenteric arteries, inhibition of NOS significantly reduced the vasodilation induced by ACh in young, adult and aged rats, indicating that NO plays a predominant role in vasorelaxation of young, adult (Fujii et al. 1993) and aged vessels. Nevertheless, the inhibition of NOS resulted in a lower reduction in aged rats than that in young and adult rats, suggesting that NO production was decreased in AChinduced vasodilation of aged rats. However, in the present study, age-related impairment of endothelial function was only partially attributed to the decreased NO production.

EDHF and $\mathrm{K}_{\mathrm{ca}}$ channels have greater significance in agonist-induced vasorelaxation in small resistance arteries. Opening of potassium channels on vascular smooth muscle cells with resultant hyperpolarization plays a central role in the distal small resistance arteries. In cerebral penetrating arterioles, activation of $\mathrm{BK}_{\mathrm{ca}}$ and $\mathrm{IK}_{\mathrm{ca}}$ channels leads to arterial hyperpolarization, contributing to ATP-induced dilation (Dietrich et al. 2008). Genes encoding for $\mathrm{SK}_{\mathrm{ca}}$ and $\mathrm{IK}_{\mathrm{ca}}$ channel subunits were highly expressed in small mesenteric arteries, stressing the importance of $\mathrm{K}_{\mathrm{ca}}$ channels in these small arteries (Hilgers et al. 2006). In the present study, we used charybdotoxin to block $\mathrm{BK}_{\mathrm{ca}}$ and $\mathrm{IK}_{\mathrm{ca}}$ channels and apamin to block $\mathrm{SK}_{\mathrm{ca}}$ channels. Both charybdotoxin and apamin significantly reduced the ACh-induced dilation in rat mesenteric arteries of young and adult rats, which provided evidences that $\mathrm{K}_{\mathrm{ca}}$ channels contribute to the ACh-induced dilation in rat small mesenteric arteries.

Age-related structural alteration in small mesenteric arteries (Laurant et al. 2004, Briones et al. 2007) is likely accompanied by a decreased expression of $\mathrm{K}_{\mathrm{ca}}$ channels, which was recently reported in small mesenteric arteries of hypertensive rats (Hilgers and Webb 2007). ROS, especially hydrogen peroxide $\left(\mathrm{H}_{2} \mathrm{O}_{2}\right)$ effectively inhibited $\mathrm{K}_{\mathrm{ca}}$ channel function (Brakemeier et al. 2003, Tang et al. 2004). Both enhanced ROS formation (Jacobson et al. 2007) and decreased expression of $\mathrm{K}_{\mathrm{ca}}$ genes could lead to the impaired $\mathrm{K}_{\mathrm{ca}}$ channel function in mesenteric arteries from aged rats, but the role of $\mathrm{K}_{\mathrm{ca}}$ channels in mesenteric arteries of aged rats has not been documented before. In the present study, apamin incubation had no effect on the ACh-induced dilation in vessels from aged rats, suggesting that $\mathrm{SK}_{\mathrm{ca}}$ channels are functionally defective in mesenteric arteries of aged rats. Blockade of $\mathrm{IK}_{\mathrm{ca}}$ and $\mathrm{BK}_{\mathrm{ca}}$ channels by charybdotoxin resulted in a significantly lower reduction of ACh-induced vasodilation in aged rats than in young and adult rats, suggesting that $\mathrm{IK}_{\mathrm{ca}}$ and/or $\mathrm{BK}_{\mathrm{ca}}$ channels are functionally impaired with age. A combined incubation of vessels with L-NMMA, charybdotoxin and apamin almost abolished ACh-induced vasodilation in young, adult and aged rats. There was no difference of the remaining dilation between these three animal groups. This further supported that $\mathrm{K}_{\mathrm{ca}}$ channels and $\mathrm{NO}$ contribute to the ACh-induced vasorelaxation in small mesenteric arteries, and both impairment of $\mathrm{K}_{\mathrm{ca}}$ channels and decreased NO production account for the age-related endothelial dysfunction.

In summary, in the present study, we showed that ACh-induced vasodilation was reduced in small resistance mesenteric arteries of aged rats; inhibition of $\mathrm{K}_{\mathrm{ca}}$ channels and NOS markedly reduced the dilation in young, adult and aged rats, but resulted in a lower reduction in vessels from aged rats. Our results suggest that ACh-induced vasodilation was impaired in mesenteric arteries of aged rats, both $\mathrm{K}_{\mathrm{ca}}$ channels and NO contribute to the vasodilation in these small resistance arteries, and the impairment of vascular 
function in small mesenteric arteries of aged rats was attributed to impaired $\mathrm{K}_{\mathrm{ca}}$ function and decreased $\mathrm{NO}$ production.

\section{Conflict of Interest}

There is no conflict of interest.

\section{References}

AMRANI M, GOODWIN AT, GRAY CC, YACOUB MH: Ageing is associated with reduced basal and stimulated release of nitric oxide by the coronary endothelium. Acta Physiol Scand 157: 79-84, 1996.

BRAKEMEIER S, EICHLER I, KNORR A, FASSHEBER T, KOHLER R, HOYER J: Modulation of Ca ${ }^{2+}$-activated $\mathrm{K}^{+}$channel in renal artery endothelium in situ by nitric oxide and reactive oxygen species. Kidney Int 64: 199207, 2003.

BRIONES AM, SALAICES M, VILA E: Mechanisms underlying hypertrophic remodeling and increased stiffness of mesenteric resistance arteries from aged rats. J Gerontol A Biol Sci Med Sci 62: 696-706, 2007.

CERNADAS MR, SÁNCHEZ DE MIGUEL L, GARCÍA-DURÁN M, GONZÁLEZ-FERNÁNDEZ F, MILLÁS I, MONTÓN M, RODRIGO J, RICO L, FERNÁNDEZ P, DE FRUTOS T, RODRÍGUEZ-FEO JA, GUERRA J, CARAMELO C, CASADO S, LÓPEZ-FARRÉ A: Expression of constitutive and inducible nitric oxide synthases in the vascular wall of young and aging rats. Circ Res 83: 279-286, 1998.

CSISZAR A, UNGVARI Z, EDWARDS JG, KAMINSKI P, WOLIN MS, KOLLER A, KALEY G: Aging-induced phenotypic changes and oxidative stress impair coronary arteriolar function. Circ Res 90: 1159-1166, 2002.

DAVIDGE ST, OJIMBA J, MCLAUGHLIN MK: Vascular function in the vitamin E-deprived rat: an interaction between nitric oxide and superoxide anions. Hypertension 31: 830-835, 1998.

DIETRICH HH, HORIUCHI T, XIANG C, HONGO K, FALCK JR, DACEY RG JR: Mechanism of ATP-induced local and conducted vasomotor responses in isolated rat cerebral penetrating arterioles. J Vasc Res 46: 253$264,2008$.

DIMITROPOULOU C, WEST L, FIELD MB, WHITE RE, REDDY LM, FALCK JR, IMIG JD: Protein phosphatase $2 \mathrm{~A}$ and $\mathrm{Ca}^{2+}$-activated $\mathrm{K}^{+}$channels contribute to 11,12-epoxyeicosatrienoic acid analog mediated mesenteric arterial relaxation. Prostaglandins Other Lipid Mediat 83: 50-61, 2007.

DORA KA, GALLAGHER NT, MCNEISH A, GARLAND CJ: Modulation of endothelial cell KCa3.1 channels during endothelium-derived hyperpolarizing factor signaling in mesenteric resistance arteries. Circ Res 102: 1247$1255,2008$.

FUJII K, OHMORI S, TOMINAGA M, ABE I, TAKATA Y, OHYA Y, KOBAYASHI K, FUJISHIMA M: Agerelated changes in endothelium dependent hyperpolarization in the rat mesenteric artery. Am J Physiol 265: H509-H516, 1993.

FUKAO M, HATTORI Y, KANNO M, SAKUMA I, KITABATAKE A: Alterations in endothelium-dependent hyperpolarization and relaxation in mesenteric arteries from streptozotocin-induced diabetic rats. $B r J$ Pharmacol 121: 1383-1391, 1997.

HILGERS RH, TODD JR, WEBB RC: Regional heterogeneity in acetylcholine-induced relaxation in rat vascular bed: role of calcium-activated $\mathrm{K}^{+}$channels. Am J Physiol 291: H216-H222, 2006.

HILGERS RH, WEBB RC: Reduced expression of $\mathrm{SK}_{\mathrm{Ca}}$ and $\mathrm{IK}_{\mathrm{Ca}}$ channel proteins in rat small mesenteric arteries during angiotensin II-induced hypertension. Am J Physiol 292: H2275-H2284, 2007.

JACOBSON A, YAN C, GAO Q, RINCON-SKINNER T, RIVERA A, EDWARDS J, HUANG A, KALEY G, SUN D: Aging enhances pressure-induced arterial superoxide formation. Am J Physiol 293: H1344-H1350, 2007.

KHAN SA, MATHEWS WR, MEISHERI KD: Role of calcium-activated $\mathrm{K}^{+}$channels in vasodilation induced by nitroglycerine, acetylcholine and nitric oxide. J Pharmacol Exp Ther 267: 1327-1335, 1993.

KNOCK GA, MAHN K, MANN GE, WARD JP, AARONSON PI: Dietary soy modulates endothelium-dependent relaxation in aged male rats: Increased agonist induced endothelium-derived hyperpolarising factor and basal nitric oxide activity. Free Radic Biol Med 41: 731-739, 2006.

KO EA, HAN J, JUNG ID, PARK WS: Physiological roles of $\mathrm{K}^{+}$channels in vascular smooth muscle cells. $J$ Smooth Muscle Res 44: 65-81, 2008. 
LAKATTA EG: Cardiovascular regulatory mechanisms in advanced age. Physiol Rev 73: 413-467, 1993.

LAURANT P, ADRIAN M, BERTHELOT A: Effect of age on mechanical properties of rat mesenteric small arteries. Can J Physiol Pharmacol 82: 269-275, 2004.

MATZ RL, SCHOTT C, STOCLET JC, ANDRIANTSITOHAINA R: Age-related endothelial dysfunction with respect to nitric oxide, endothelium-derived hyperpolarizing factor and cyclooxygenase products. Physiol Res 49: 11$18,2000$.

MINAMINO T, KOMURO I: Vascular aging: insights from studies on cellular senescence, stem cell aging, and progeroid syndromes. Nat Clin Pract Cardiovasc Med 5: 637-648, 2008.

MULLER-DELP JM, SPIER SA, RAMSEY MW, DELP MD: Aging impairs endothelium-dependent vasodilation in rat skeletal muscle arterioles. Am J Physiol 283: H1662-H1672, 2002.

NAGAI Y, METTER EJ, EARLEY CJ, KEMPER MK, BECKER LC, LAKATTA EG, FLEG JL: Increased carotid artery intimal-medial thickness in asymptomatic older subjects with exercise-induced myocardial ischemia. Circulation 98: 1504-1509, 1998.

SANTHANAM L, CHRISTIANSON DW, NYHAN D, BERKOWITZ DE: Arginase and vascular aging. $J$ Appl Physiol 105: 1632-1642, 2008.

SOBEY CG: Potassium channel function in vascular disease. Arterioscler Thromb Vasc Biol 21: 28-38, 2001.

SUN D, HUANG A, KOLLER A, KALEY G: Decreased arteriolar sensitivity to shear stress in adult rats is reversed by chronic exercise activity. Microcirculation 9: 91-97, 2002.

SUN D, HUANG A, YAN EH, WU Z, YAN C, KAMINSKI PM, OURY TD, WOLIN MS, KALEY G: Reduced release of nitric oxide to shear stress in mesenteric arteries of aged rats. Am J Physiol 286: H2249-H2256, 2004.

TADDEI S, VIRDIS A, GHIADONI L, SALVETTI G, BERNINI G, MAGAGNA A, SALVETTI A: Age-related reduction of NO availability and oxidative stress in humans. Hypertension 38: 274-279, 2001.

TANG XD, GARCIA ML, HEINEMANN SH, HOSHI T: Reactive oxygen species impair Slo1 BK channel function by altering cysteine-mediated calcium sensing. Nat Struct Mol Biol 11: 171-178, 2004.

WOODMAN CR, PRICE EM, LAUGHLIN MH: Aging induces muscle-specific impairment of endothelium-dependent dilation in skeletal muscle feed arteries. J Appl Physiol 93: 1685-1690, 2002.

ZHANG DX, GAUTHIER KM, CHAWENGSUB Y, CAMPBELL WB: Ach-induced relaxations of rabbit small mesenteric arteries: role of arachidonic acid metabolites and $\mathrm{K}^{+}$. Am J Physiol 293: H152-H159, 2007. 